\title{
Understanding and applying a resource-based relative value system to your neurosurgical practice
}

\author{
Gregory J. Przybylski, M.D. \\ Department of Neurosurgery, Northwestern University, Chicago, Illinois
}

\begin{abstract}
The payment policy for United States physicians was formerly based on determination of customary and prevailing charges from their fee schedules. Rapidly growing health care expenditures in the 1980s led to a fundamental change in payment reimbursement in which the new system was based on the resource costs to the physician for providing health care services. This reform highlights the significant regulatory morass that has come to burden the health care industry. One of the most critical changes in physician reimbursement was caused by the Congressional mandate that led to the development of a resource-based relative value scale (RBRVS) for the creation of the Medicare physician fee schedule. Most physicians, however, have limited familiarity with the RBRVS system, which now serves as the basis for Medicare-related physician reimbursement as well as many third-party payers. A historical review of the development of the RBRVS will serve as the basis for applying the methodology to improve the effectiveness of the neurosurgeon's practice.
\end{abstract}

KEY WORDS • relative value unit • resource-based relative value system - fee schedule

Understanding payment systems by which physicians are reimbursed for their services has not been emphasized in practice management until the past decade. The progressive reduction in reimbursement to physicians has drawn significant attention to the education of physicians in modern coding and reimbursement systems, which serve as the basis for these changes. Moreover, recent federal investigations into alleged fraudulent Medicare billing practices have demonstrated that an understanding of these methods is essential for the physician. In this paper, the author reviews the historical evolution of reimbursement methods. By appreciating the underlying rationale of these methods, neurosurgeons can adapt the relative value system to manage their practice successfully.

\section{MEDICARE PHYSICIAN REIMBURSEMENT PRIOR TO REFORM}

Through the 1980s, a fee-for-service payment method

Abbreviations used in this paper: AMA = American Medical Association; $\mathrm{CPEP}=$ Clinical Practice Expert Panel; CPR = customary, prevailing, and reasonable; $\mathrm{CPT}=$ Current Practice Terminology; DRG = diagnosis-related group; HCFA = Health Care Finance Group; OBRA = Omnibus Budget Reconciliation Act; PPRC = Physician Payment Review Commission; RBRVS = ResourceBased Relative Value Scale; RUV = Relative Value Update Committee; RVS = relative value system; SMS = Socioeconomic Monitoring System. was used by health care insurers, in which physician reimbursement was based on CPR charges. Because physician payment schedules served as the basis for determining reimbursement, there was little motivation to understand payment methodology. The alarming growth of health care expenditures, however, did attract the attention of both government and private insurers interested in controlling escalating costs.

During the mid-1980s, total health care expenditures had reached $\$ 540$ billion annually, representing an $11 \%$ share of the gross national product, doubling the 5.6\% share paid in 1965 when the Medicare system was created. ${ }^{9}$ Moreover, Medicare reimbursement for physician services grew at a $15 \%$ compound rate between 1975 and 1987, nearly twice the $7.9 \%$ growth of the gross national product. ${ }^{11}$ Concerns were raised about the medical necessity of these services and their contribution to escalating costs. ${ }^{2,3}$ This set the stage for governmental regulation of health care reimbursement methods.

Attention was first drawn to hospital services, which accounted for more than two thirds of Medicare expenditures. In 1983, a prospective pricing system was established for the hospital services reflected in Medicare Part A. A DRG payment was created for hundreds of diseases based on their national mean cost of hospital care. Although it was assumed in this method that the cost for providing care to patients in whom illness severity varied would eventually equal the calculated DRG payment, ad- 
ditional payments were also authorized to account for unusually severe illnesses that required prolonged hospital stays. Because the payment was identical regardless of the hospital cost, the prospective pricing system provided a strong incentive for hospitals to improve cost efficiency. This method successfully reduced annual growth of Medicare expenditures by more than half between 1975 and 1990.

Several factors influenced the decision to develop an alternative method of physician payment, including dissatisfaction with the original payment scheme, growing Medicare Part B expenditures, and a reasonable proposal for a new method. The original method for determining the physician's payment schedule was based on CPR charges, resembling the usual, customary, and reasonable charge system utilized by private insurers. To reduce some of these costs, the HCFA defined customary physician charges as the median of an individual physician's charges for a specific service within a specific time interval. In contrast, the prevailing charge was defined as the fee in the 90th percentile charged by specialty-specific physicians within a Medicare payment area. Finally, the reasonable charge reflected the lower of the customary and prevailing charges.

The wide variation in the amount Medicare paid for physician services, however, both among physician specialties as well as among geographical regions, caused dissatisfaction within the medical profession. ${ }^{1}$ Initially, costs were reduced by targeting the 75 th percentile prevailing charge. Subsequently, Medicare introduced a temporary price freeze on physician services. This method of control was replaced in 1976 by relating increases in prevailing charges to the Medicare Economic Index, which measures the annual growth of physician practice costs based both on 1971 actual charges as well as overall economic trends. As a result, Medicare payments were based on prevailing charges in 1971 and remained nearly unchanged until 1992. Additional dissatisfaction grew among physicians because of the increasing disparity between the lower valuation of patient evaluation and management services and procedural services.

After a second freeze on payment levels in the 1980s and reduced payments for "overpriced" surgical procedures, several payment reform proposals were suggested by the government. Although additional modifications to CPR were considered, it seemed this method evolved into a complex system that no longer reflected physician's costs. Consideration was given to developing a DRG system similar to that developed for hospital payments under Medicare Part A. ${ }^{10}$ Another option was to create a managed care or capitation model of payment. Finally, a proposal was offered for replacing the CPR method with a payment schedule based on an RVS.

Only the CPR and the payment schedule represented fee-for-service methods. Many physicians voiced concern that a DRG- or capitated payment-based system would threaten clinical judgment in patient-care decisions. Moreover, the AMA opposed policies that prevented physicians from charging patients the difference between their fee and the Medicare payment (that is, balance billing). Because the courts supported congressional legislation to limit physicians' fees, development of an RVS seemed to provide the best alternative to the CPR method.

\section{Development of the RBRVS}

In 1986, Congress created the PPRC to develop a new physician reimbursement model in the Medicare system. Although the commission recommended the development of a Medicare Fee Schedule, ${ }^{12}$ the payment methodology based on CPR was a major contributor to spiraling health care expenditures in the first place. Two years later, the commission recommended a fundamental policy change in which the fee schedule was based on resource costs rather than typical physician charges. ${ }^{13}$ Consequently, the RBRVS system was developed, representing a dramatic change by which the uninhibited growth pattern of health care expenditures of the previous decade was reduced. After the HCFA adopted the RBRVS for determining physician payment by Medicare, other third-party insurance companies have likewise accepted this system.

This payment methodology, implemented in 1992, has had the greatest impact on the billing practices of physicians during the past decade and represents the first major change in establishing how physicians were paid for their services since the inception of the Medicare program in 1965. The concept of an RVS, however, was not new. In fact, the California Medical Association developed an RVS in 1956 that was regularly updated for nearly two decades.

It was, however, based on a median of charges reported by California Blue Shield in 1969, thereby still representing a CPR charge methodology; physicians used this method to determine fee schedules, and government and private insurers alike used the system to establish payment rates. Growing concerns raised by the Federal Trade Commission regarding the possibility of antitrust violations led the California Medical Association to discontinue updating the charge-related data.

Rather than continuing to pursue a charge-based RVS as supported by most surgical subspecialty societies, an RBRVS system was considered in which physician services were ranked according to the relative costs incurred in providing them. Most nonprocedural specialty societies believed that wide variations among fees for services as well as geographical variations failed to adequately reflect service-related costs. As a result, the AMA chose to support an RVS based on resource costs provided that the payment system reflected geographical variations in practice costs and did not prevent physicians from balance billing. Although the AMA submitted a proposal to the HCFA for development of a new RVS, continued antitrust concerns precluded direct physician involvement in their development. Consequently, the AMA accepted a proposal submitted by the Harvard University School of Public Health to perform a national study of RBRVSs for physician services.

On July 1, 1986, the Consolidated OBRA mandated that the Department of Health and Human Services develop an RBRVS to be submitted to Congress. In addition, this law charged the PPRC with studying a variety of alternative options for Medicare payment reform including changing CPR, capitation, and physician DRG. ${ }^{12}$ The PPRC recommended development of a payment schedule linked to an RBRVS. ${ }^{13}$

Concurrently, the Harvard study commenced in December of 1985, receiving funding from the HCFA. The prin- 
cipal investigators, William Hsiao, Ph.D., and Peter Braun, M.D., had previously encountered limited success in a 1979 pilot study in which they attempted to rank 27 physician services from five specialties. ${ }^{8}$ Five years later, in a follow-up study, they demonstrated more consistent results after estimates of work alone without the addition of complexity were considered. In the first phase of the HCFA-supported national study an RBRVS for 12 physician specialties was developed. In addition, independent funding was obtained for study of six additional specialties. Specialty-specific scales were developed, as was a method for creating cross-specialty links that allowed integration of a single cross-specialty RBRVSs. The OBRA of 1986 provided a 2-year extension for submission of RBRVS to Congress as well as mandated inclusion of 15 additional specialties during the second phase of the study..$^{4-7}$

Although the AMA adopted in principle the results of the Harvard study, they also recommended that the new Medicare payment system include geographical differences in practice costs and professional liability, as well as a transition period to prevent disruptive changes between the CPR and RBRVS systems. The PPRC likewise endorsed the study and supported the AMA recommendations. The commission, however, diverged from the AMA on two issues. Despite opposition to balance billing, the commission recommended placing limits on this practice. In addition, expenditure targets for Medicare spending were also recommended. Because RBRVS was still a variation of a fee-for-service payment system, the PPRC believed that cost containment could only be achieved with expenditure targets.

\section{TRANSITION TO THE RBRVS}

In December 1989, Congress enacted the OBRA of 89, which mandated a Medicare Fee Schedule based on the RBRVS reported in the Harvard study with inclusion of physician work, practice expense, and professional liability costs. Geographical adjustments to all three components were included (Fig. 1). The conversion factor for the calculated RVU was based on keeping the overall Medicare expenditure the same as that when the CPR system was used. A process was created by which the conversion factor was adjusted annually, maintaining a "budget-neutral" value, which limited increases in expenditures to $\$ 20$ million annually. Additional reductions in limits on balance billing were included.

A 5-year transition to the RBRVS Medicare payment system was to begin on January 1, 1992. Despite more than 7 years of investigation undertaken in the Harvard study, RVUs had not been assigned to all services listed in the CPT by this date. At the direction of HCFA, regional

$$
\begin{aligned}
\mathrm{MFS}= & {[\mathrm{RVUw} \times \mathrm{GPCIw})+(\text { RVUpe } \times \text { GPCIpe }) } \\
& +\mathrm{RVUm} \times \text { GPCIm })] \times \mathrm{CF}
\end{aligned}
$$

Fig. 1. Medicare payment for a physician service calculated using the RVS system. Abbreviations: MFS = medicare fee schedule; $\mathrm{RVU}=$ relative value unit GPCI $=$ geographical practice cost index; $\mathrm{W}=$ work; $\mathrm{PE}=$ practice expense; $\mathrm{M}=$ malpractice; $\mathrm{CF}=$ conversion factor. carrier medical directors assigned RVUs to the remaining codes until the third phase of the study was completed. The final comprehensive RBRVS for physician services was published in the November 25, 1992, Federal Register.

After HCFA implemented the RBRVS fee schedule for payments by Medicare, other health insurers implemented an RVSs as well. In the RBRVS physician work, practice expense, and malpractice expense are used as the components for determining the relative value of a particular service. The physician work component is approximately $54 \%$ of the total relative value of the service, whereas practice expense is $41 \%$. In addition, a geographical practice-cost index is incorporated to adjust for geographical differences.

To coordinate changes in CPT with HCFA-assigned RVUs, the AMA/Specialty RUC was created in 1991. Twenty-three of the 28 members are appointed by major national medical specialty societies; the other five include the RUC chair, the cochair of the Health Care Professionals Advisory Committee, and members of the AMA, American Osteopathic Association, and CPT editorial panel. An RUC advisory committee composed of members appointed by 94 specialty societies develop and suggest RVUs for new codes to the RUC. Specialty society representatives are responsible for compiling data obtained from physician surveys to determine the time spent in performing the medical service and ranking the service relative to existing services. Subsequently, consensus recommendations are forwarded to the HCFA annually for consideration. During the 5-year period ending in 1998, nearly 2300 RVU recommendations were made to the HCFA, with a recent acceptance rate of greater than $90 \%$.

The Balanced Budget Act, however, required a budgetneutral conclusion. Because the development of new CPT codes requires subsequent valuation, the newly assigned RVU must come from previously valued codes to maintain budget neutrality. Typically, values are maintained within a family of codes such as the musculoskeletal or neurosurgical sections of the CPT manual. Consequently, there is a disincentive to making significant changes in codes. Some allowance for new technology exists to account for innovations in medical care, thereby creating an opportunity for growth within a family of codes. The methods of maintaining budget neutrality have included reductions in practice expense as well as changes in the conversion factor. Beginning in 1996, the HCFA decided that annual budget neutrality adjustments would be made to the physician fee schedule conversion factor (Fig. 2).

Although work valuations were resource based, practice expense was based on the AMA's SMS 1989 Core Survey of a representative sample of 4000 physicians in 34 specialties. Practice costs, however, including office rent, wages for nonphysician personnel, equipment and supplies, were measured overall rather than specific to a given service. Moreover, practice expenses varied among specialties, representing $52.2 \%$ of family physicians' practice costs but only $38.9 \%$ of neurosurgeons' costs. The method enacted by OBRA of 89 involved multiplying the specialty-specific practice expense factor by the mean Medicare payment of the service in 1991. Similarly, professional liability was calculated based on the proportion 


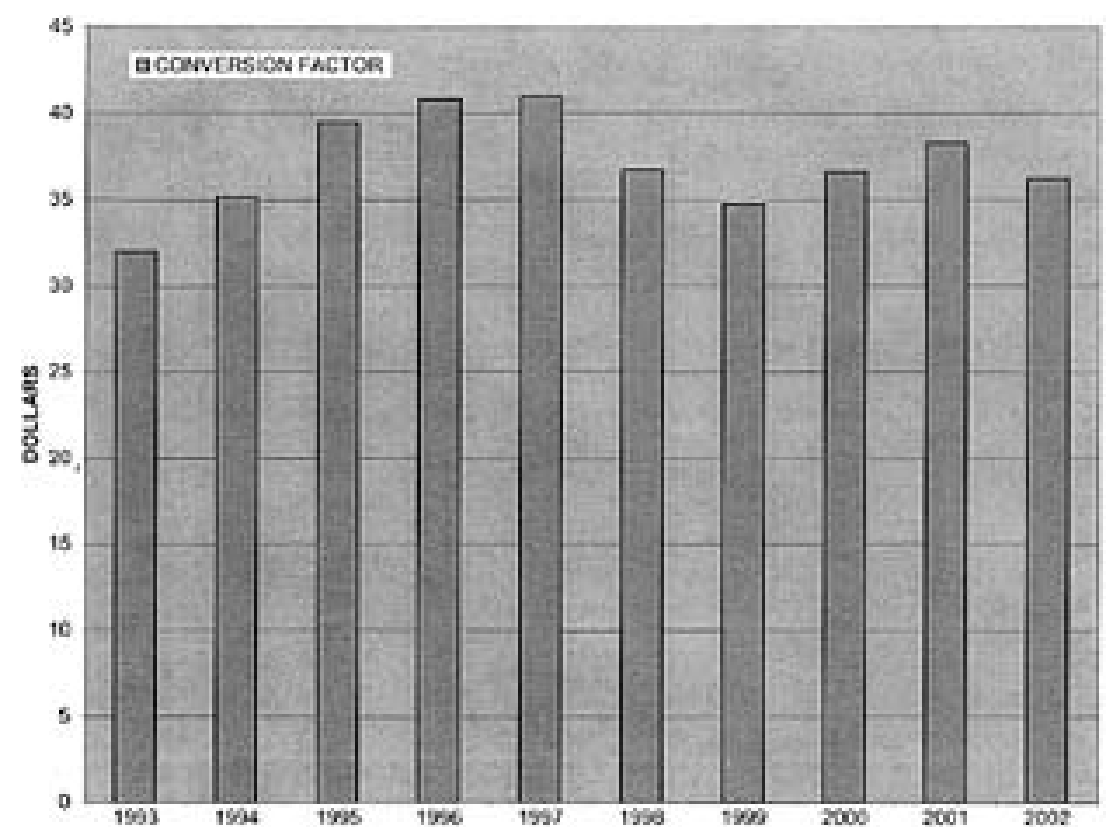

Fig. 2. Variation in Medicare's conversion factor over the past 10 years.

of cost multiplied by the Medicare payment. The mean neurosurgical professional liability component of practice cost was $7.6 \%$, compared with a $3.9 \%$ proportion for the family physician. If the service was provided by more than one specialty, a weighted mean of surveyed costs was used.

The OBRA of 1993 mandated reductions in the practice expense of "over-valued" services. Over a 3-year period, the practice expense was reduced annually by $25 \%$ of the amount by which the value exceeded the physician work RVU until it was no greater than $128 \%$ of the work component. Concerns over the nonresource-based OBRA of 89 methods of calculating practice expense as well as a 1994 Social Security Act amendment mandating resourcebased practice expense calculations, however, prompted the HCFA to contract with Abt Associates, Inc., to perform a national study of physicians' practice expenses. Medical associations nominated 15 CPEPs which were charged with developing a list of direct cost components of a selected group of reference codes. In addition, a national survey was mailed to 5000 practices to obtain a sample of practice costs and service mix to validate the CPEP estimates. Poor response rates, however, led the HCFA to abandon efforts at obtaining actual survey data. To meet the January 1998 deadline set by Congress, the HCFA planned to implement new practice expense values based on CPEP data. When the CPEP data could not be validated with actual practice expense information and the actual differences in practice cost could not be accounted for among all specialties, the AMA urged Congress to extend the deadline for implementation of new practice expense values. Congress not only delayed implementation until 1999, it also directed the General Accounting Office to review the HCFA's methodology and make recommendations for a valid resource-based model. Results of the General Accounting Office's report supported the concerns raised by the AMA.
Beginning in January 1999, the HCFA initiated a transition to a resource-based practice expense valuation that differs based on the site of the service. If a medical service can be performed either in an office or a hospital, then both a nonfacility- and facility-derived practice expense value will be assigned. Whereas locations assigned nonfacility practice expense include physician offices and independent neuroimaging or laboratory centers, facility practice expense is attributed to hospitals, surgical centers, and nursing homes. The method for estimating practice costs is based on the AMA's SMS data. Because the SMS data were derived from small sample sizes in which there was sufficient variability to introduce sampling bias, there continues to be concern regarding this methodology.

\section{Adapting the Neurosurgical Practice to the RBRVS}

Although the RVS represents the most common system for determining physician reimbursement, it is critical for neurosurgeons to understand that it can be adapted to improve the financial effectiveness of their practices. In fact, an RVS system can be implemented to develop an effective fee schedule, to determine the practice costs for providing physician services, and to provide a basis for negotiating contracts with third-party payers.

Because physician reimbursement is no longer based on customary charges, one might consider the process of assigning charges as somewhat arbitrary. The lack of critical attention to the specific charges assigned at the CPT code level, however, can result in establishing some fees below the level commonly paid by insurers. At the other extreme, excessively inflated charges may cause patients to experience "sticker shock" upon receipt of the physician's bill. Because consumers are accustomed to "paying the bill" outside of the health care system, they often incorrectly assume that their insurer will be responsible for paying the physician based on their charges. It is no won- 
der that there is little sympathy among consumers and Congressional representatives for physicians who have seen their rates of reimbursement reduced over the last decade.

Using the RVS system, a fee schedule can be developed by which charges to CPT codes are assigned based on the relative amount of physician work required to provide the service. At the same time, it is imperative to assign charges that account for the costs of providing the service as well. Consequently, the neurosurgeon should first identify the costs required to provide physician services.

In every practice management system one should be able to track the various practice-related costs. These expenses range from overhead costs such as rent and utilities to personnel costs for nurses, secretaries, and billing agents. In addition, malpractice costs have become one of the most rapidly growing neurosurgery-related expenditures in many states that have not adopted tort reform. Once these costs are determined for a given period of time, however, one must then determine the amount of physician work that was provided during that same time interval. At this point, the RVS system becomes an effective tool. By calculating the physician work component of the relative value of each surgical procedure as well as evaluation and management service provided during the interval, the cost to provide a single unit of physician work can be determined. This is the critical step in identifying appropriate charges that will cover the expenses to provide services.

After the physician understands the cost incurred in providing units of work, the practice can more effectively negotiate with third-party payers. Without knowing the cost to provide a particular service, how can one determine whether the payer-recommended reimbursement schedule will meet the fixed costs of providing the service? Although physicians, to prevent loss in the volume of patients, are often frightened into signing contracts in which reimbursement does not equal their costs, this strategy requires concurrent expansion of services provided to patients whose insurers reimburse at levels that exceed one's cost to pay for the deficit. Few businesses can survive for extended periods of time charging consumers less than the cost of the product being sold.

The neurosurgeon must be cognizant of the methods by which third-party payers may determine the reimbursement schedule. Although the physician may be satisfied with an agreement that provides reimbursement at some mean proportional factor that exceeds the Medicare Fee Schedule, higher payments may be assigned to uncommon or unusual services while lower payments are assigned to the common service. Although the mean payment among all possible services may be acceptable, most practices perform only a limited proportion of the potential neurosurgical services that are defined in CPT.

\section{CONCLUSIONS}

There has been a dramatic change in the method of phy- sician reimbursement in association with the broad acceptance of the RVS system. Whereas reimbursement was previously based on charges, rapid escalation of spending for medical services resulted in the evolution of a system that allows more effective cost containment. The RBRVS represents a significant shift from a payment method based on charges to one based on the costs for providing medical services. Although this system is used by Medicare and many third-party payers to determine physician reimbursement, the neurosurgeon can also take advantage of this methodology to develop more effective practice management tools that can lead to a more successful practice.

\section{References}

1. Burney IL, Schieber GJ, Blaxall MO, et al: Geographic variation in physician's fees. Payments to physicians under Medicare and Medicaid. JAMA 240:1368-1371, 1978

2. Chassin MR, Kosecoff J, Park RE, et al: Does inappropriate use explain geographic variations in the use of health care services? A study of three procedures. JAMA 258:2533-2537, 1987

3. Greenspan AM, Kay HR, Berger BC, et al: Incidence of unwarranted implantation of permanent cardiac pacemakers in a large medical population. N Engl J Med 318:158-163, 1988

4. Hsiao WC, Braun P, Becker ER, et al: The Resource-Based Relative-Value Scale. Toward the development of an alternative physician payment system. JAMA 258:799-802, 1987

5. Hsiao WC, Braun P, Dunn D, et al: Resource-based relative values. An overview. JAMA 260:2347-2353, 1988

6. Hsiao WC, Braun P, Dunn D, et al: Results and policy implications of the resource-based relative-value study. N Engl J Med 319:881-888, 1988

7. Hsiao WC, Braun P, Yntema D, et al: Estimating physicians' work for a resource-based relative-value scale. N Engl J Med 319:835-841, 1988

8. Hsiao WC, Stason WB: Toward developing a relative value scale for medical and surgical services. Health Care Financ Rev 1:23-38, 1979

9. Jacobs P: The Economics of Health and Medical Care, ed 3. Gaithersberg, MD: Aspen Publishers, 1991, pp 168-174

10. Mitchell JB: Physician DRGs. N Engl J Med 313:670-675, 1985

11. Roper WL: Statement before Subcommittee on Health of the Committee on Ways and Means, U.S. House of Representatives. Washington DC: US Department of Health and Human Services, Health Care Finance Administration, 1988

12. United States. Physician Payment Review Commission: Medicare Physician Payment: Washington DC: Physician Payment Review Commission, 1987

13. United States. Physician Payment Review Commission: Report to Congress. Physician Payment Review Commission. Washington DC: Physician Payment Review Commission, 1988

Manuscript received February 27, 2002.

Accepted in final form March 28, 2002.

Address reprint requests to: Gregory J. Przybylski, M.D., 233 East Erie Street, Suite 614, Chicago, Illinois 60611. email: gprzybylski@nmff.org. 